\title{
Correction to: Liminal Legality Among Mixed-Status Latinx Families: Considerations for Critically Engaged Clinical Practice
}

\author{
Jocelyn Terrazas $^{1} \cdot$ Bertranna Alero Muruthi $^{2}$ (D) $\cdot$ Reid E. Thompson Cañas ${ }^{3} \cdot$ Jeffrey B. Jackson $^{1} \cdot$ J. Maria Bermudez $^{4}$
}

Published online: 8 August 2020

(c) Springer Science+Business Media, LLC, part of Springer Nature 2020

Correction to: Contemporary Family Therapy

https://doi.org/10.1007/s10591-020-09545-7

The original version of this article unfortunately contained an error in the co-author name.

The author name should be Jeffrey B. Jackson instead it was published incorrectly as Jeffrey Jackson.

Publisher's Note Springer Nature remains neutral with regard to jurisdictional claims in published maps and institutional affiliations.

The original article can be found online at https://doi.org/10.1007/ s10591-020-09545-7.

Bertranna Alero Muruthi

Muruthba@uoregon.edu

Jocelyn Terrazas

jocelt1@vt.edu

Reid E. Thompson Cañas

rthompso@uoregon.edu

Jeffrey B. Jackson

jjax@vt.edu

J. Maria Bermudez

maria.bermudez@uga.edu

1 Department of Human Development and Family Science,

Marriage and Family Therapy Program, Virginia Tech,

Falls Church, VA, USA

2 Department of Counseling Psychology and Human Services, Couple and Family Therapy Program, University of Oregon, Eugene, OR 97404, USA

3 Department of Counseling Psychology and Human Services, University of Oregon, Eugene, OR 97404, USA

4 Department of Human Development and Family Science, Marriage and Family, Therapy Program University

of Georgia, Athens, GA 30606, USA 